\title{
Изучение физико-химических и сорбционных свойств гексацианофрерратов никеля и железа по отношению к цезию
}

\author{
® 2019 Семенищев В.С. ${ }^{1}$, Пьянков А.А. ${ }^{1}$, Ремез В.П. ${ }^{2}$, \\ Афонин Ю.Д. ${ }^{1}$, Никифоров А.Ф. ${ }^{1}$ \\ ${ }^{1}$ Уральский федеральныий университет, Екатеринбург \\ ${ }^{2}$ ООО НПП «Эксорб», Екатеринбург
}

Поступила в редакцию 8.06.2019 г.

DOI: $10.17308 /$ sorpchrom.2020.20/2380

\begin{abstract}
Очистка различных жидких сред от техногенных радионуклидов является важной технологической задачей, для решения которой часто используются сорбционные методы. Целью данной работы было изучение физико-химических и сорбционных характеристик образцов чистых гексацианоферрата железа (образцы 1 и 2) и гексацианоферрата никеля (образцы 3 и 4) по отношению к радионуклидам цезия. Показано, что с точки зрения гранулометрического состава, влияющего на скорость седиментации и легкость фильтрации, гексацианоферраты железа имеют технологическое преимущество перед гексацианоферратами никеля благодаря тому, что последние содержат большее количество мелкой фракции (0.5-10 мкм). Результаты термогравиметрического анализа и дифференциального термического анализа показали, что нижний предел температурной стабильности для всех изученных сорбентов составляет не менее $200^{\circ} \mathrm{C}$, что позволяет беспрепятственно сушить насыщенные сорбенты при температуре $100-150^{\circ} \mathrm{C}$. При этом гексацианоферраты никеля обладают несколько большей термической стабильностью по сравнению с гексацианоферратами железа. На модельных растворах показано отсутствие влияния $\mathrm{pH}$ раствора сорбцию цезия гексацианоферратами никеля и железа в диапазоне от 0.5 до 11.5. Коэффициенты распределения цезия во всем изученном интервале рН варьируются от $3 \cdot 10^{4}$ до $3 \cdot 10^{5} \mathrm{~cm}^{3} / \Gamma$. Изучено влияние концентрации натрия и калия на сорбцию цезия гексацианоферратами никеля и железа при содержании ионов $\mathrm{Na}^{+}$и $\mathrm{K}^{+}$до 2.5 моль/дм ${ }^{3}$. Показано, что сорбция цезия гексацианоферратами железа не зависит от концентрации натрия и калия, тогда как коэффициенты распределения цезия для гексацианоферратов никеля незначительно снижаются при концентрациях натрия и калия более 1 моль/дм³. При этом коэффициенты распределения цезия при любых изученных условиях составляют не менее $10^{4} \mathrm{~cm}^{3} /$. Таким образом, изученные гексацианоферраты можно рекомендовать для извлечения цезия из широкого спектра среднеактивных ЖРО, содержащих цезий.
\end{abstract}

Ключевые слова: жидкие радиоактивные отходы, цезий, гексацианоферраты, сорбция.

\section{Введение}

В процессе производственной деятельности человека образуются значительные количества техногенных отходов, в частности сточные воды, содержащие различные токсичные примеси. К наиболее токсичным компонентам сточных вод относятся радиоактивные элементы, которые могут попадать в окружающую среду в результате деятельности предприятий ядерного топливного цикла, атомных электростанций, а также при авариях на радиационно-опасных объектах. Для очистки природных и сточных вод от радионуклидов широко используются сорбционные методы [1]. Среди продуктов деления и активации самую серьезную проблему представ- 
ляют радионуклиды с периодом полураспада в пределах 10-100 лет, из которых наиболее значимыми являются ${ }^{137} \mathrm{Cs},{ }^{90} \mathrm{Sr},{ }^{60} \mathrm{Co}$. Среди этих радионуклидов особое место занимает ${ }^{137} \mathrm{Cs}$, который обусловливает порядка 95\% гамма-излучения от облученного ядерного топлива после пятилетней выдержки. В качестве сорбентов для цезия используют природные глинистые минералы [2-4], органические ионообменные смолы [5], активированные угли [6], титаносиликаты щелочных металлов [7, 8], а также экстракционно-хроматографические смолы на основе краун-эфиров [9]. Наибольшая селективность к цезию характерна для органических и неорганических сорбционно-активных материалов, модифицированных гексацианоферратами переходных металлов [10-12], фосфомолибдатами [13, 14] и вольфраматами [15]. Среди недостатков модифицированных сорбентов можно отметить относительно низкую емкость и кинетические затруднения, связанные с тем, что сорбционной активностью обладает лишь часть материала. Целью данной работы было изучить влияние мешающих факторов (pH, концентрации ионов-аналогов) на сорбцию ${ }^{137} \mathrm{Cs}$ гексацианоферратами железа и никеля, а также изучение их физико-химических свойств, имеющих значение в технологии переработки жидких радиоактивных отходов.

\section{Эксперимент}

Были исследованы физико-химические и сорбционные свойства четырех образцов гексацианоферратов производства ООО НПП «Эксорб» (Россия): двух образцов гексацианоферрата железа и двух образцов гексацианоферрата никеля, синтезированных различным способом. Описание сорбентов представлено в табл. 1.

Таблица 1. Описание сорбентов

\begin{tabular}{|c|c|c|}
\hline Образец & $\begin{array}{c}\text { Промышленное } \\
\text { название }\end{array}$ & Описание \\
\hline 1 & $\mathrm{FFe}$ & Гексацианоферрат железа, лабораторный образец \\
\hline 2 & $\mathrm{FFe}-\mathrm{In}$ & Гексацианоферрат железа, промышленный образец \\
\hline 3 & $\mathrm{FNi}$ & Гексацианоферрат никеля, лабораторный образец \\
\hline 4 & $\mathrm{FNi}-\mathrm{In}$ & Гексацианоферрат никеля, промышленный образец \\
\hline
\end{tabular}

Сорбенты получали прямым осаждением в водной среде гексацианоферрата железа-калия и сульфата железа (II) либо сульфата никеля (II). Лабораторные образцы получали на лабораторном оборудовании, размер партии - 100 г. Промышленные партии сорбентов изготавливали на промышленном общехимическом оборудовании, размер партии - 1000 кг. Полученную суспензию фильтровали, промывали осадок водой, сушили при температуре $100^{\circ} \mathrm{C}$, после чего измельчали. Измельчение лабораторных образцы проводили в лабораторном миксере, а промышленных - в дезинтеграторе.

Определение удельной поверхности образцов, оценка размеров пор и определение параметров поверхности проводилось с использованием низкотемпературной адсорбцией азота $\left(-196^{\circ} \mathrm{C}\right)$ на приборе NOVA 1200е компании Quantachrome. Время дегазации образцов перед исследованием при температуре $100^{\circ} \mathrm{C}$ составляло 1 час.

Определение гранулометрического состава сорбентов производили на лазерном дифракционном анализаторе гранулометрического состава Fritsch Analysette 22 MicroTec plus с блоком диспергирования в жидкости - Wet Dispersion Unit. Для измерения на приборе отбирали представительную пробу сорбента. Измерение проводили в ячейке диспергирования в водопроводной воде. Диапазон измерения от 0.08 мкм до 2000 мкм. 
Термогравиметрический и дифференциальный термический анализ был выполнен в воздушной среде на установке Mettler Toledo Stare TGA/SDTA851e LF/1600 с микровесами МТ5. Скорость нагрева составляла $10^{\circ} \mathrm{C} / \mathrm{Mин.} \mathrm{Скорость} \mathrm{продувки}$ воздуха составляла $50 \mathrm{~cm}^{3} /$ мин. Масса навески сорбентов составляла от 40 до 50 мг.

Измерение активности проб проводили на альфа-бета-радиометре для измерений малых активностей УМФ-2000 и гамма-бета-спектрометре МКС-АТ1315.

\section{Обсуждение результатов}

Изучение физико-химических свойств сорбентов. На рисунке 1 представлены дифференциальные и интегральные кривые распределения размеров частиц для каждого из изученных сорбентов. Результаты обработки кривых представлены в таблице 2.
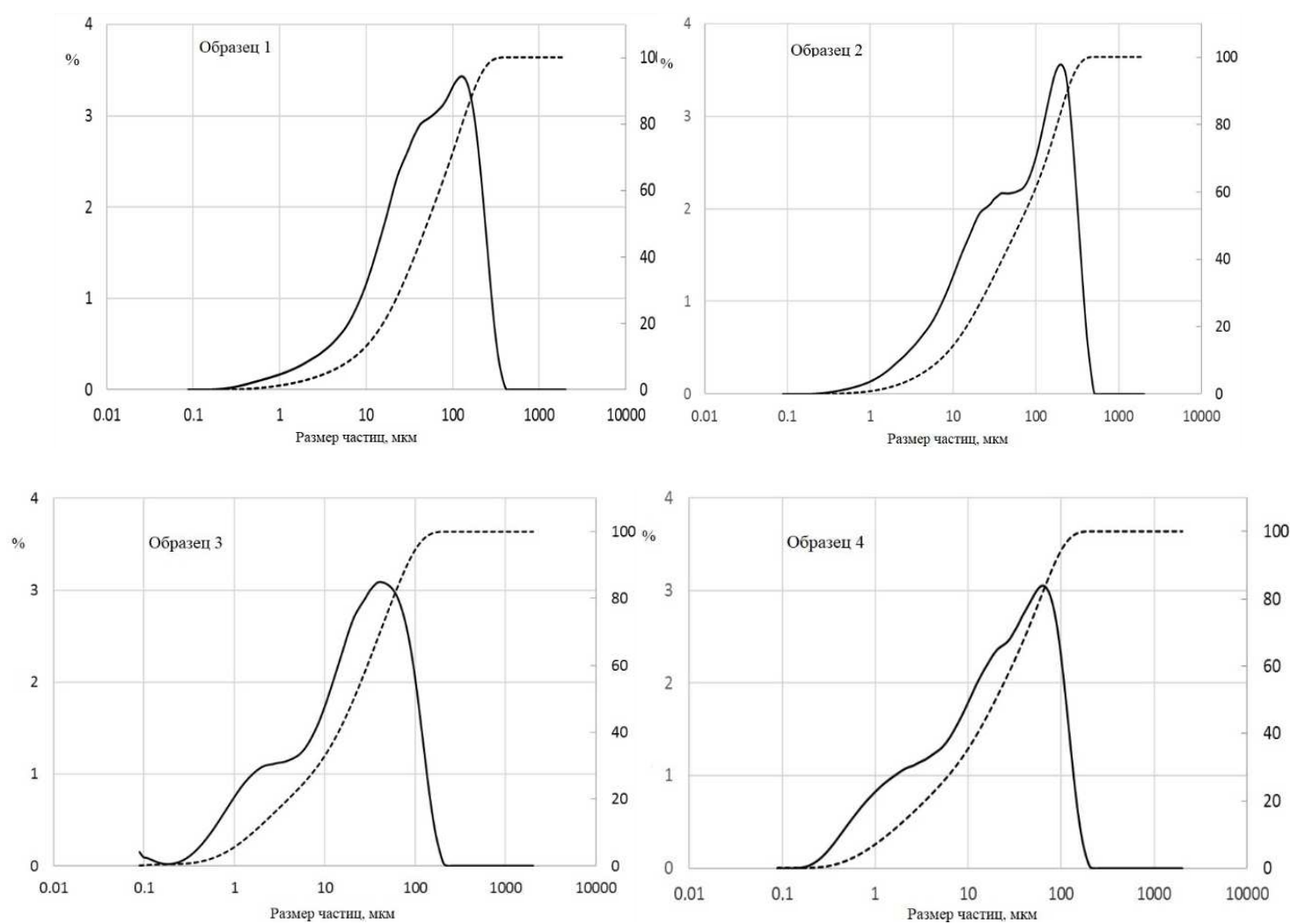

Рис. 1. Кривые распределения размеров частиц гексацианоферратных сорбентов (сплошная линия - дифференциальная кривая, пунктирная - интегральная кривая)

Таблица 2. Распределение частиц гексацианоферратных сорбентов по фракциям и удельная поверхность сорбентов

\begin{tabular}{|c|c|c|c|c|c|}
\hline Сорбент & $\begin{array}{c}\text { Фракция } \\
1, \text { мкм }\end{array}$ & $\begin{array}{c}\text { Фракция } \\
2, \text { мкм }\end{array}$ & $\begin{array}{c}\text { Фракция } \\
3, \text { мкм }\end{array}$ & $\begin{array}{c}80 \% \text { частиц лежит в диа- } \\
\text { пазоне, мкм }\end{array}$ & $\mathrm{S}, \mathrm{m}^{2} / \Gamma$ \\
\hline 1 & 70 & - & - & $8-170$ & $30 \pm 2$ \\
\hline 2 & 35 & 200 & - & $10-250$ & $113 \pm 2$ \\
\hline 3 & $<0.1$ & 35 & 70 & $1-80$ & $16 \pm 2$ \\
\hline 4 & 1 & 25 & 70 & $1-80$ & $43 \pm 5$ \\
\hline
\end{tabular}

Результаты исследования гранулометрического состав сорбентов, можно заметить, что сорбенты 2, 3, 4 имеют сложный состав. Гексацианоферраты никеля (3) и 
(4) по сравнению с гексацианоферратами железа (1) и (2) в целом представлены более мелкими частицами. При этом промышленный вариант измельчения приводит к образованию чуть большего количества мелкой фракции. Малые размеры частиц обуславливают большую удельную поверхность, и, как следствие, высокую степень и скорость сорбции, но более сложное отделение твердой фазы при фильтрации. Фильтрация через трековые мембраны показала себя неэффективной, вследствие пропускания части сорбента через мембрану и большого времени фильтрации. В дальнейшем при исследовании сорбционных свойств разделение твердой и жидкой фаз осуществляли на центрифуге Beckman Coulter Allegra x-30 на скорости 7500 об/мин в течение 10 минут.

Различия в распределениях по крупности частиц для разных сорбентов, очевидно, приводят и к различной удельной поверхности этих сорбентов. Из таблицы 2 видно, что для образца 1 удельная поверхность в 3.5 раза меньше, чем для образца 2 , что можно объяснить как наличием большего количества более мелкой фракции в образце 2 , так и, по-видимому, особенностями измельчения образцов. Аналогично, в случае гексацианоферратов никеля, удельная площадь поверхности промышленного образца (4) оказалась в 3 раза больше, чем у лабораторного образца (3). Тот факт, что для гексацианоферратов никеля характерна существенно меньшая удельная поверхность, чем для гексацианоферратов железа, можно объяснить тем, что для гексацианоферратов железа, вероятно, характерна большая пористость.

Таким образом, с точки зрения механических свойств (в первую очередь, скорости осаждения и легкости фильтрации) гексацианоферраты железа (сорбенты 1 и 2) имеют преимущество перед гексацианоферратами никеля (3 и 4) благодаря меньшему количеству мелкой фракции, которая имеет низкую скорость оседания и забивает поры фильтра.

В результате сорбционной переработки ЖРО потребуется дальнейшая сушка насыщенных сорбентов. Также при высоких удельных активностях возможно значительное разогревание насыщенного сорбента. В то же время, воздействие высоких температур, как правило, приводит к деструкции сорбента или его перекристаллизации, что уменьшает его емкость. Кроме того, известно, что гексацианоферраты переходных металлов, как правило, склоны к разложению при повышенных температуpax.

Для определения возможности температурной деструкции сорбентов было изучено термическое поведение образцов сорбентов с помощью термогравиметрического (TGA) и дифференциального термического (SDTA) анализа в интервале температур 45-500 ${ }^{\circ} \mathrm{C}$ на воздухе (рис. 2).

Результаты показали, что разных сорбентов характерны различные диапазоны термической устойчивости. Так, минимальная термическая устойчивость наблюдалась для гексацианоферратов железа (начало разложения гексацианоферратной фазы для сорбентов 1 и 2 наблюдалось при температурах около $220^{\circ} \mathrm{C}$ ), тогда как гексацианоферраты никеля оказались более устойчивыми. Наилучшие характеристики наблюдались на образце 3: начало разложения наблюдается при температуре порядка $320^{\circ} \mathrm{C}$. Убыль массы для всех сорбентов при низких температурах (до 150-180 ${ }^{\circ} \mathrm{C}$ ) можно объяснить удалением воды, что также подтверждается эндотермичностью данного процесса. При более высоких температурах убыль массы обусловлена начинающимся разложением гексацианоферратов. В таблице 3 приведены суммарные характеристики термического поведения сорбентов. 

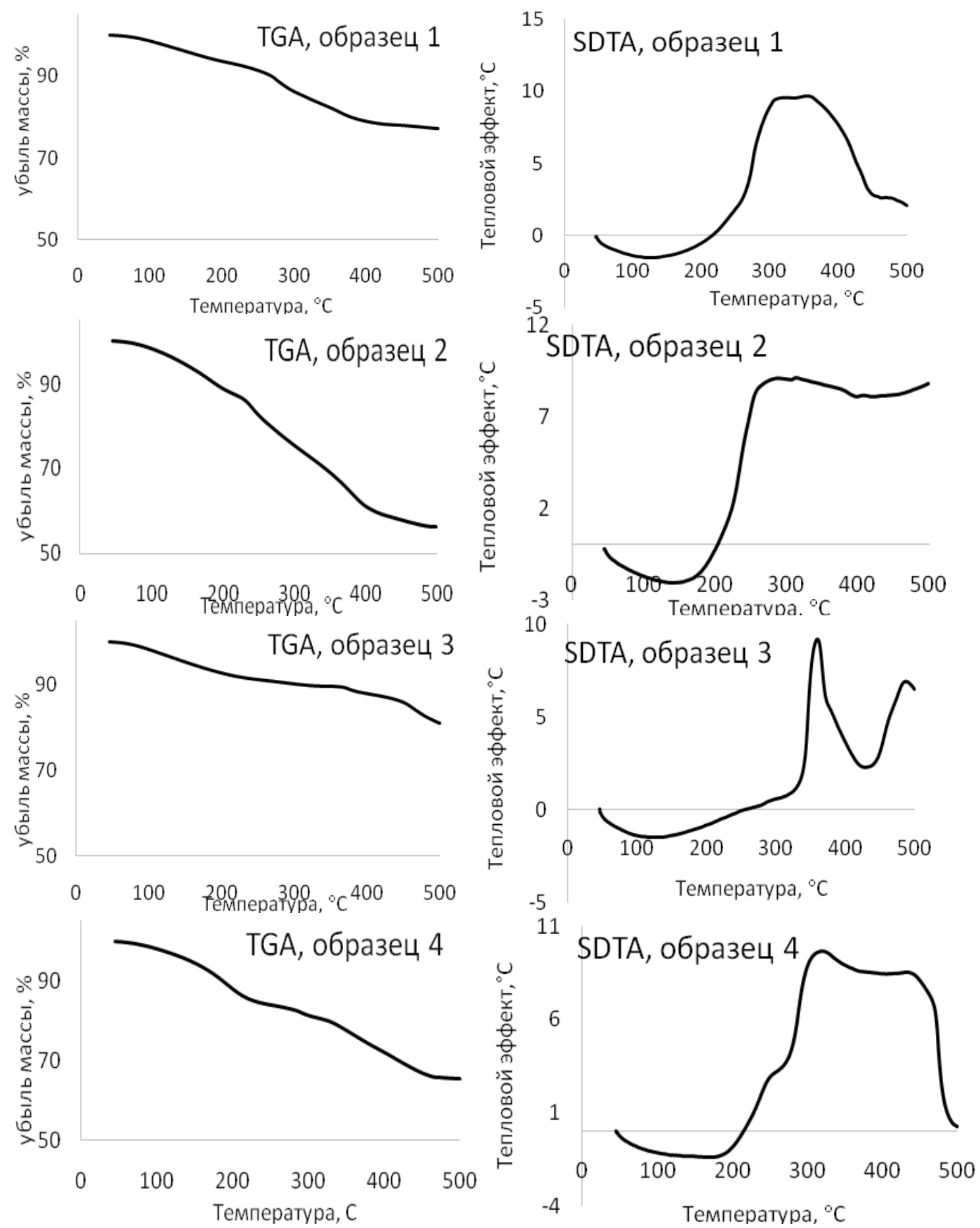

Рис. 2. Кривые TGA и SDTA сорбентов в интервале температур $45-500^{\circ} \mathrm{C}$ на воздухе

Таблица 3. Результаты TGA и SDTA гексацианоферратов железа и никеля

\begin{tabular}{|c|c|c|c|}
\hline Сорбент & Убыль массы при $500{ }^{\circ} \mathrm{C}, \%$ & Начало разложения, ${ }^{\circ} \mathrm{C}$ & Пик разложения, ${ }^{\circ} \mathrm{C}$ \\
\hline 1 & 20 & 220 & 340 \\
\hline 2 & 40 & 220 & 290 \\
\hline 3 & 19 & 320 & 360 \\
\hline 4 & 35 & 230 & 310 \\
\hline
\end{tabular}

Таким образом, результаты термогравиметрического анализа и дифференциального термического анализа показали, что нижний предел температурной стабиль- 
ности для всех изученных сорбентов составляет не менее $220^{\circ} \mathrm{C}$, при этом гексацианоферраты никеля обладают большей термической стабильностью по сравнению с гексацианоферратами железа. Наибольшая термическая стабильность наблюдалась для образца 3.

Изучение сорбции ${ }^{137} \mathrm{Cs}$ гескацианоферратами. Поскольку сорбция цезия гексацианоферратами протекает по ионообменному механизму, на сорбцию будет влиять концентрация конкурирующих катионов, в первую очередь водорода и щелочных металлов. В работе было изучено влияние $\mathrm{pH}$ на сорбцию цезия гексацианоферратами железа и никеля. В качестве растворов была взята отстоянная и отфильтрованная водопроводная вода с добавлением стабильного цезия $\left(0.05 \mathrm{мг} /\right.$ дм $\left.^{3}\right)$ и метки ${ }^{137} \mathrm{Cs}$. pH растворов задавали внесением необходимых количеств растворов $\mathrm{NaOH}$ и $\mathrm{HCl}$. Зависимости «lgKd - pH» для каждого сорбента представлены на рисунке 3.
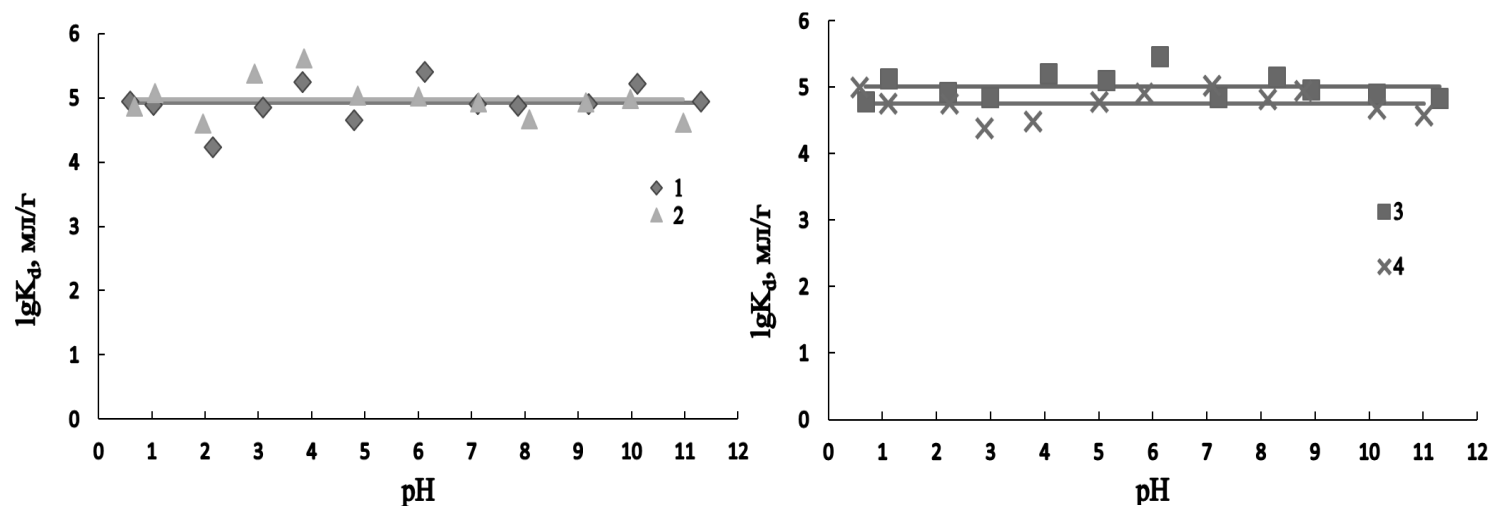

Рис. 3. Зависимость коэффициентов распределения цезия от $\mathrm{pH}$

По полученным зависимостям видно, что $\mathrm{pH}$ раствора в диапазоне 0.5-11.5 не влияет на коэффициент распределения для гексацианоферратов всех типов. При этом коэффициенты распределения цезия во всем изученном интервале $\mathrm{pH}$ варьируются от $3 \cdot 10^{4}$ до $3 \cdot 10^{5}$ дм $^{3} /$.

В техногенных ЖРО, так и в радиоактивно-загрязненных природных водах могут наблюдаться повышенные концентрации натрия, калия и аммония. Поскольку они являются химическими аналогами цезия, представляло интерес изучить влияние этих конкурирующих ионов на сорбцию ${ }^{137} \mathrm{Cs}$. На рисунках 4-6 представлены зависимости «lgKd-C(Me $\left.{ }^{+}\right) »$ для каждого сорбента.
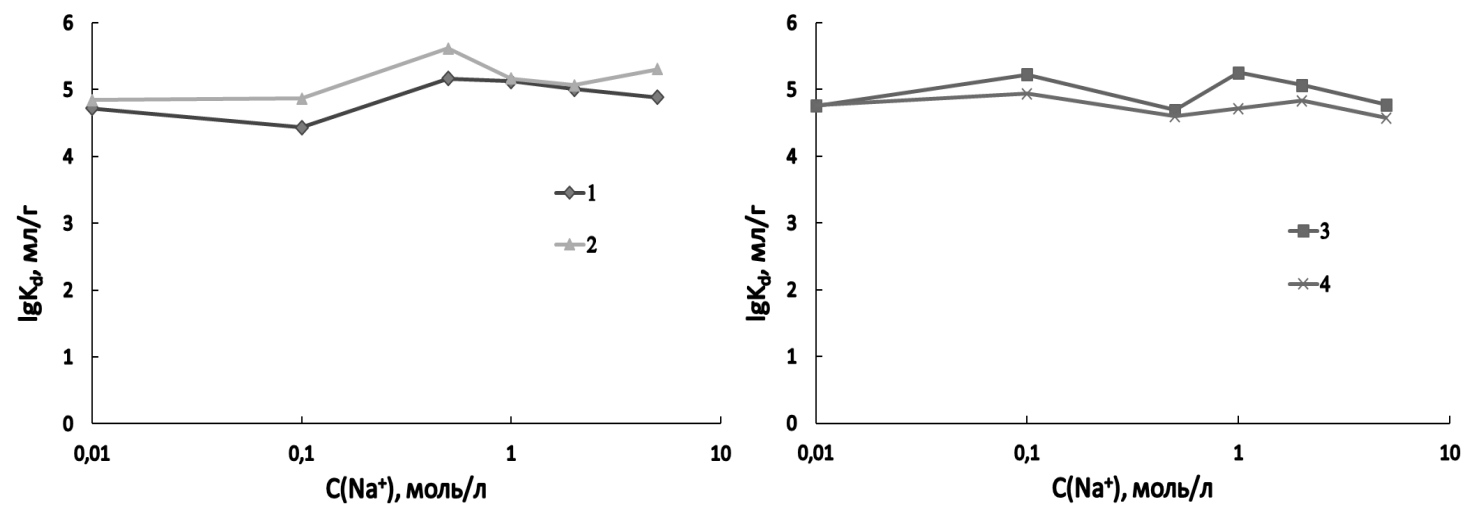

Рис. 4. Зависимость коэффициентов распределения цезия от концентрации натрия 

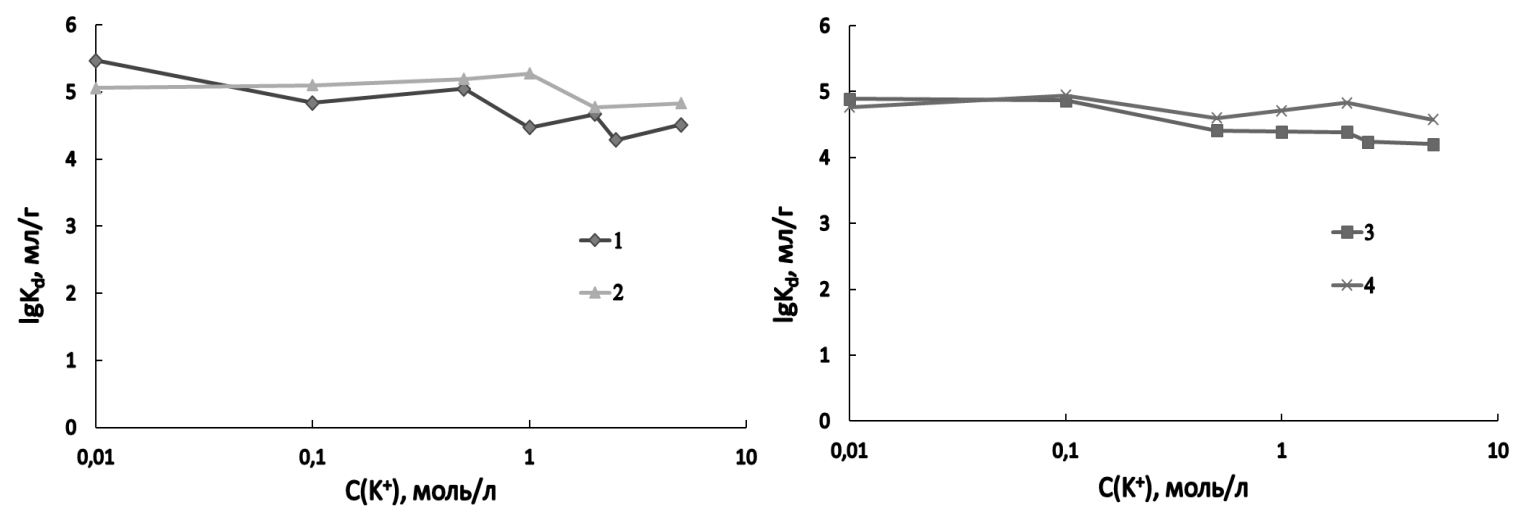

Рис. 5. Зависимость коэффициентов распределения цезия от концентрации калия

Из представленных зависимостей видно, что коэффициент распределения не изменяется при содержании ионов $\mathrm{Na}^{+}$и $\mathrm{K}^{+}$в диапазоне 0.01-5 моль/дм ${ }^{3}$ для гексацианоферратов железа. Для гексацианоферратов никеля наблюдается небольшое снижение коэффициента распределения цезия в области высоких концентраций $\mathrm{Na}^{+}$ и $\mathrm{K}^{+}$(более 1 моль/дм $\left.{ }^{3}\right)$. При этом коэффициенты распределения цезия составляют не менее $10^{4} \mathrm{~cm}^{3} / \Gamma$.
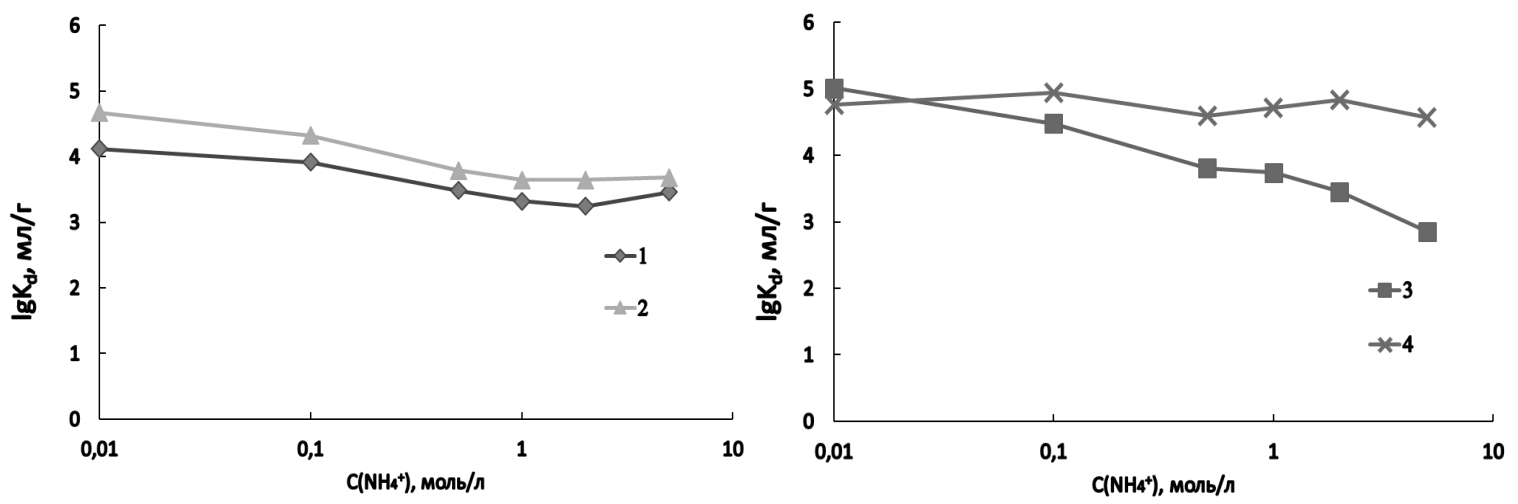

Рис. 6. Зависимость коэффициентов распределения цезия от концентрации аммония

В отличие от натрия и калия, ионы аммония оказывают заметно большее подавляющее влияние на сорбцию цезия, которое становится заметным уже при концентрации аммония от 0.5 моль/ дм ${ }^{3}$. Полученные результаты хорошо согласуются с литературными данными по сорбции ионов щелочных металлов и аммония гексацианоферратами переходных металлов. Как было показано Вольхиным и др. [16], гексацианоферраты сорбируют ионы щелочных металлов за счет цеолитного эффекта, который проявляется тем сильнее, чем ближе диаметр сорбируемого иона к размерам сечения каналов в структуре гексацианоферрата. Максимальный цеолитный эффект наблюдается для катиона цезия, наиболее близок к иону $\mathrm{Cs}^{+}$по размеру ион $\mathrm{NH}_{4}{ }^{+}$(см. табл. 4), поэтому ион аммония оказывает большее влияние на сорбцию цезия, чем катионы других рассматриваемых элементов. Тем не менее, даже при концентрации аммония 5 моль/дм ${ }^{3}$ коэффициенты распределения цезия остаются не менее $10^{3} \mathrm{~cm}^{3} / \Gamma$.

Таким образом, изученные гексацианоферраты можно рекомендовать для извлечения цезия из ЖРО в широком интервале $\mathrm{pH}$ (от 0.5 до 11.5), а также в широком 
диапазоне концентраций конкурирующих катионов натрия, калия и аммония (до 5 моль/дм ${ }^{3}$ ).

Таблица 4. Эффективные диаметры гидратированных катионов щелочных металлов и аммония [17].

\begin{tabular}{|c|c|c|c|c|}
\hline Катион & $\mathrm{Na}^{+}$ & $\mathrm{K}^{+}$ & $\mathrm{Cs}^{+}$ & $\mathrm{NH}_{4}{ }^{+}$ \\
\hline Диаметр катиона, нм & $0.4-0.45$ & 0.3 & 0.25 & 0.25 \\
\hline
\end{tabular}

\section{Заключение}

Были изучены физико-химические и сорбционные характеристики образцов гексацианоферрата железа (образцы 1 и 2) и гексацианоферрата никеля (образцы 3 и 4). С точки зрения гранулометрического состава, влияющего на скорость седиментации и легкость фильтрации, гексацианоферраты железа (сорбенты 1 и 2) имеют технологическое преимущество перед гексацианоферратами никеля (3 и 4) благодаря меньшему количеству мелкой фракции. Результаты термогравиметрического анализа и дифференциального термического анализа показали, что нижний предел температурной стабильности для всех изученных сорбентов составляет не менее $200^{\circ} \mathrm{C}$, при этом гексацианоферраты никеля обладают несколько большей термической стабильностью по сравнению с гексацианоферратами железа. Показано отсутствие влияния pH раствора сорбцию цезия гексацианоферратами никеля и железа в диапазоне от 0.5 до 11.5. Коэффициенты распределения цезия во всем изученном интервале $\mathrm{pH}$ варьируются от $3 \cdot 10^{4}$ до $3 \cdot 10^{5} \mathrm{~cm}^{3} / \Gamma$. Изучено влияние концентрации натрия и калия на сорбцию цезия гексацианоферратами никеля и железа при содержании ионов $\mathrm{Na}^{+}$, $\mathrm{K}^{+}$и $\mathrm{NH}_{4}{ }^{+}$до 5 моль/дм ${ }^{3}$. Показано, что сорбция цезия гексацианоферратами железа не зависит от концентрации натрия и калия, тогда как коэффициенты распределения цезия для гексацианоферратов никеля незначительно снижаются при концентрациях натрия и калия более 1 моль/дм³. При этом коэффициенты распределения цезия при любых изученных условиях составляют не менее $10^{4} \mathrm{~cm}^{3} / \Gamma$. Ионы аммония оказывают заметно большее подавляющее влияние на сорбцию цезия, которое становится заметным уже при концентрации аммония от 0.5 моль/дм ${ }^{3}$, что объясняется близостью радиусов гидратированных ионов $\mathrm{Cs}^{+}$и $\mathrm{NH}_{4}{ }^{+}$. Таким образом, изученные гексацианоферраты можно рекомендовать для извлечения цезия из широкого спектра среднеактивных ЖРО, содержащих цезий.

\section{Список литературы}

1. Милютин В.В., Некрасова Н.А., Харитонов О.В., Фирсова Л.А. и др. // Сорбиионные и хроматографические прочессы. 2016. T. 16. № 3. C. 313-322.

2. Кутергин А.С., Бетенеков Н.Д., Недобух Т.А., Воронина А.В. // Сорбичинные и хроматографические прочессы. 2006. Т. 6. № 6. C. $1198-1202$.

3. Коноплева И.В. // Сорбиионные и хроматографические прочессы. 2016. Т. 16. № 4. C. $446-456$.

4. Леонтьева Т.Г., Москальчук Л.Н., Баклай А.А., Маковская Н.А. // Сорбционные и хроматографические процессы. 2018. Т. 18. № 5. C. 726-735.

5. Egorin A., Palamarchuk M., Tokar E., Tutov M. et al. // Radiochim. Acta. 2017. Vol. 105. Issue 2. pp. 121-127.

6. Свешникова Д.А., Хамизов Р.Х., Рабаданов К.Ш., Амиров А.М. и др. // Сорбционные и хроматографические прочессы. 2015. T. 15. №. 4. C. 478-485.

7. Стрелко В.В., Милютин В.В., Гелис В.М., Псарева Т.С. И др. // Радиохимия. 2015. T. 57. № 1. С. 64-68. 
8. Милютин В.В., Некрасова Н.А., Яничева Н.Ю., Калашникова Г.О. и др. // Радиохимия. 2017. T. 59. № 1. С. 59-62.

9. Kumar V., Sharma J.N., Achuthan P.V., Hubli R.C. // J Radioanal Nucl Chem. 2014. Vol. 299. Issue 3. pp 1547-1553.

10.Kamenik J., Dulaiova H., Sebesta F., Stastna K. // J. Radioanal Nucl Chem. 2013. Vol. 296. Issue 2. pp. 841-846.

11.Воронина А.В., Ноговицына Е.В., Бетенеков Н.Д. // Сорбиионные и хроматографические прочессы. 2006. Т.6. № 6. С. 960-964.

12.Авраменко В.А., Железнов В.В., Сокольницкая Т.А., Чередниченко А.И. и др. // Сорбиионные и хроматографические проuесcbl. 2006. T.6. № 6. C. 899-904.
13.Pike S.M., Buesseler K.O., Breier C.F., Dulaiova H. et al. // J Radioanal Nucl Chem. 2013. Vol. 296. Issue 1. pp. 369-374.

14.Shady S.A. // J Hazard Mater. 2009. Vol. 167. pp. 947-952.

15.El-Naggar I.M., Zakaria E.S., Ali I.M., Khalil M. et al. // J. Environ Radioact. 2012. Vol. 112. pp. 108-117.

16.Вольхин В.В., Колесова С.А., Зильберман М.В., Онорин С.А. // Журнал неорганической химии. 1971. № 6. С. 1611-1613.

17.Золотов Ю. А., Дорохова Е. Н., Фадеева В. И. Основы аналитической химии. М. Высшая школа. ч. 1. 1999. 351 с.

\title{
The study of physicochemical and sorption characteristics of nickel and iron hexacyanoferrates with respect to cesium
}

\author{
Semenishchev Vladimir S. ${ }^{1}$, Pyankov Atemiy A. ${ }^{1}$, Remez Victor P. ${ }^{2}$, \\ Afonin Yuriy D. ${ }^{1}$, Nikiforov Alexandr F. ${ }^{1}$ \\ ${ }^{1}$ Ural Federal University, Ekaterinburg \\ ${ }^{2}$ Eksorb Ltd., Ekaterinburg
}

The decontamination of liquid media contaminated by anthropogenic radionuclides provides a serious technological challenge. Sorption methods are often used to perform this task. The paper studies the physico-chemical and sorption characteristics of pure samples of iron (samples 1 and 2) and nickel (samples 3 and 4) hexacyanoferrates with respect to caesium radionuclides. It is shown that iron hexacyanoferrates have better granulometric composition than nickel hexacyanoferrates due to a smaller quantity of fine fraction $(0.5-10 \mu \mathrm{m})$, thus providing for easier sedimentation and filtration. The results of thermal gravimetric and differential thermal analysis have shown that the lower limit of thermal stability of all hexacyanoferrates was at least $200^{\circ} \mathrm{C}$. This means that spent sorbents can be dried at $100-150^{\circ} \mathrm{C}$. Nickel hexacyanoferrates demonstrated a slightly higher thermal stability as compared with iron hexacyanoferrates. The experiment performed with simulated solutions demonstrated that $\mathrm{pH}$ does not affect the sorption of caesium by hexacyanoferrates with the $\mathrm{pH}$ range of 0.5 to 11.5 . The distribution coefficients of caesium varied from $3 \cdot 10^{4}$ to $3 \cdot 10^{5} \mathrm{~cm}^{3} / \mathrm{g}$. The effect of sodium and potassium on the sorption of cesium by iron and nickel hexacyanoferrates was studied at the concentrations of $\mathrm{Na}^{+}$and $\mathrm{K}^{+}$of up to $5 \mathrm{~mol} / \mathrm{dm}^{3}$. The study demonstrates that the sorption of caesium by iron hexacyanoferrates does not depend on sodium and potassium concentration; whereas in case of nickel hexacyanoferrates distribution coefficients of caesium slightly decrease with concentrations of sodium and potassium of $1 \mathrm{~mol} / \mathrm{dm}^{3}$ and higher. However, distribution coefficients of caesium remained at least $10^{4} \mathrm{~cm}^{3} / \mathrm{g}$ under any of the conditions studied. Ammonium ions showed significantly stronger suppressing effect on caesium sorption at the concentration of $0.5 \mathrm{~mol} / \mathrm{dm}^{3}$, which can be explained by similar ionic radii of hydrated $\mathrm{Cs}^{+}$and $\mathrm{NH}_{4}{ }^{+}$. Thus, the iron and nickel hexacyanoferrates can be recommended for caesium separation from a wide spectrum of acidic, neutral, slightly alkaline and salty intermediate-level liquid radioactive wastes.

Keywords: Liquid radioactive waste, caesium, hexacyanoferrates, sorption

\section{References}

1. Milyutin V.V., Nekrassova N.A., Kharitonov O.V., Firsova L.A. et al., Sorbtsionnye $i$ khromatographicheskie protsessy,2016, Vol. 16, No 3, pp. 313-322. 
2. Kutergin A.S., Betenekov N.D., Nedobukh T.A., Voronina A.V., Sorbtsionnye i khromatographicheskie protsessy, 2006, Vol. 6, No 6, pp. 1198-1202

3. Konopleva I.V., Sorbtsionnye i khromatographicheskie protsessy, 2016, Vol. 16, No 4, pp. 446-456.

4. Leontyeva T.G., Moskalchuk L.N., Baklai A.A., Makovskaya N.A., Sorbtsionnye i khromatographicheskie protsessy, 2018, Vol. 18, No 5, pp. 726-735.

5. Egorin A., Palamarchuk M., Tokar E., Tutov M. et al., Radiochim. Acta, 2017, Vol. 105, Issue 2, pp. 121-127. DOI: https://doi.org/10.1515/ract-2015-2522

6. Sveshnikova D.A., Khamizov R.Kh., Rabadanov K.Sh., Amirov A.M. et al., Sorbtsionnye $i$ khromatographicheskie protsessy,2015, Vol. 15, No 4, pp. 478-485.

7. Strelko V.V., Milyutin V.V., Gelis V.M., Psareva T.S. et al., Radiochemistry, 2015, Vol. 57, Issue 1, pp. 73-78. DOI: https://doi.org/10.1134/S1066362215010117

8. Milyutin V.V., Nekrasova N.A., Yanicheva N.Yu., Kalashnikova G.O. et al., Radiochemistry, 2017, Vol. 59, Issue 1, pp. 65-69. DOI: https://doi.org/10.1134/S1066362217010088

9. Kumar V., Sharma J.N., Achuthan P.V., Hubli R.C., J Radioanal Nucl Chem., 2014, Vol. 299, Issue 3, pp 1547-1553. DOI: https://doi.org/10.1007/s10967-014-2973-9

Семенищев Владимир Сергеевич - доцент кафедры радиохимии и прикладной экологии, к.х.н., доцент, Уральский федеральный университет, Екатеринбург

Пьянков Артемий Александрович - магистрант кафедры радиохимии и прикладной экологии, Уральский федеральный университет, Екатеринбург

Ремез Виктор Павлович - директор ООО НПП «Эксорб», д.т.н., Екатеринбург

Афонин Юрий Дмитриевич - доцент кафедры редких металлов и наноматериалов, к.т.н., доцент, Уральский федеральный университет, Екатеринбург

Никифоров Александр Федорович - профессор кафедры радиохимии и прикладной экологии,
д.х.н., профессор, Уральский федеральный университет, Екатеринбург
10. Kamenik J., Dulaiova H., Sebesta F., Stastna K., J. Radioanal Nucl Chem, 2013, Vol. 296, Issue 2, pp. 841-846. DOI: https://doi.org/10.1007/s10967-012-2007-4

11. Voronina A.V., Nogovitsyna E.V., Betenekov N.D., Sorbtsionnye $i$ khromatographicheskie protsessy, 2006, Vol. 6, No 6, pp. 960964.

12.Avramenko V.A., Zheleznov V.V., Sokol'nickaja T.A., Cherednichenko A.I. et al., Sorbtsionnye i khromatographicheskie protsessy, 2006, Vol. 6, No 6, pp. 899-904.

13.Pike S.M., Buesseler K.O., Breier C.F., Dulaiova H. et al., J. Radioanal Nucl Chem, 2013, Vol. 296, Issue 1, pp. 369-374. DOI: https://doi.org/10.1007/s10967-012-2014-5

14.Shady S.A., J Hazard Mater, 2009, Vol. 167, pp. 947-952. DOI: https://doi.org/10.1016/j.jhazmat.2009.01.084

15.El-Naggar I.M., Zakaria E.S., Ali I.M., Khalil M., El-Shahat M.F., J Environ Radioact, 2012, Vol. 112, pp. 108-117. DOI: https://doi.org/10.1016/j.jenvrad.2012.05.012

16. Vol'hin V.V., Kolesova S.A. Zil'berman M.V., Onorin S.A., Rus J Inorg Chem, 1971, Vol. 6, pp. 1611-1613.

17.Zolotov Yu.A., Dorohova E.N., Fadeeva V.I. Osnovy analiticheskoj himii, M., Vysshaja shkola Publ., pt. 1, 1999, 351 p.

Semenishchev Vladimir S. - Ph.D (chemistry), associated professor, department of radiochemistry and applied ecology, Ural Federal University, Yekaterinburg, e-mail: vovius82@ mail.ru

Pyankov Artemiy A. - master student, department of radiochemistry and applied ecology, Ural Federal University, Yekaterinburg, e-mail: artsnz@mail.ru

Remez Viktor P. - grand Ph.D. (techn), CEO of Eksorb Ltd., Yekaterinburg, e-mail: sorb@bk.ru

Afonin Yuriy D. - Ph.D (techn), associated professor, department of rare metals and nanomaterials, Ural Federal University, Yekaterinburg, email: j.d.afonin@urfu.ru

Nikiforov Alexandr F. - grand Ph.D. (chemistry), professor, department of radiochemistry and applied ecology, Ural Federal University, Yekaterinburg, email: alex.f.nikiforov@mail.ru 